Journal of the Egyptian Society of Parasitology, Vol.43, No.2, August 2013

J. Egypt. Soc. Parasitol., 43(2), 327-332

\title{
HELICOBACTER PYLORI AND EGYPTIAN INFANTILE COLIC
}

\author{
By \\ ADEL S.A. Ali ${ }^{1}$ and Maher B.M. Borei ${ }^{2}$ \\ Departments of Pediatrics ${ }^{1}$ and Clinical Pathology ${ }^{2}$, Faculty of Medicine, \\ Zagazig University, (email:Adel_sherif@yahoo.com) Zagazig, Egypt
}

\begin{abstract}
Excessive infant crying is a common and often stress-inducing condition for parents that can ultimately result in infant abuse. Although the infantile colic is reported commonly and causes appreciable distress for both parents and pediatricians, its pathogenesis remains unclear, despite 40 years of research. This work studied the role of $H$. pylori in infantile colic. This study was conducted in a primary health care office in Sharkia Governorate. The study included 50 infants with infantile colic according to Wessel's criteria, along with age and sex matched 50 healthy controls. All infants without apparent cause for their colic underwent full history taking, clinical examination and H. pylori antigen in their stools. This study supports the new evidence for the role of $\mathrm{H}$. pylori in the pathogenesis of infantile colic. H. pylori stool antigen was present in $31(62 \%)$ of cases in contrast to $10(20 \%)$ of controls $(\mathrm{P}<0.0001)$. Normal vaginal delivery, male, vomiting and breast feeding may be risk factors for $H$. pylori infection in this age period.
\end{abstract}

Keywords: Egypt, H. pylori, infants, infantile colic.

\section{Introduction}

Infantile colic refers to a behavioral syndrome occurring during the first 3 months of life (Talachian et al, 2008). Excessive crying of young infants is common and often a serious problem for parents (Reijneveld et al, 2001). Despite its potentially substantial negative health consequences no consensus has been reached on the definition of excessive crying often called infantile colic. By far the most widely used quantitative definition of colic is the one proposed by Wessel et al known as the rule of threes. Infants are considered to have colic if they cry for more than 3 hour a day, for more than 3 days a week, and for more than 3 weeks (Ghosh et al, 2004). It is usually selflimiting, without long term adverse consequences, but also can be distressing and frustrating for parents. Estimates of cumulative incidence have varied from $10-40 \%$ (Herman and Le, 2007). The cause of infantile colic remains unclear. Underlying organic causes of excessive crying must be considered during the evaluation. Organic causes account for less than 5 percent of infants presenting with excessive crying. Gastrointestinal, psychosocial, and neurodevelopmental 
disorders have been suggested as the cause of colic (Roberts et al, 2004).

Helicobacter pylori is a gram-negative bacillus colonizes gastric mucosa in humans (Özen et al, 2006). Despite the fact that $H$. pylori was discovered 32 years ago and that the Nobel Prize in Medicine was awarded to Marshall and Warren 8 years ago, H. pylori infection is still a challenging subject for many researchers and physicians (Talley and Richter, 2006). It is one of the most common chronic bacterial infections worldwide; infecting more than half of the world's population (Kato and Sherman, 2005). Persistent H. pylori infection led to serious pathogenesis as gastric cancer, peptic ulcer, and other gastrointestinal diseases (Algood and Cover, 2006).

Infection causes recurrent abdominal pain (Gijsbers et al, 2006) and sometimes severe infantile colic (Abdelrazak, M 2012). Abdelrazak published his case-control study, where cases were 55 infants age 2 weeks to four months of age who were diagnosed with colic according to Wessel' criteria. The controls were 20 healthy babies matched by country of origin, age, sex, and ethnicity. A stool antigen test was used to test for H.pylori. The researcher found that more than $80 \%$ of babies with colic tested positive for $\mathrm{H}$ pylori, compared to only $23 \%$ of infants without colic - for an odds ratio of 15.3 (Abdelrazak, 2012). Although this is the first study about the association of H. pylori and infantile colic, this study is unable to tell if this relationship is causal. Indeed, it does not even determine with any assurance what the mechanism between $\mathrm{H}$. pylori and colic is. Regardless, it is a somewhat striking and interesting result. Future work could examine if treating $H$. pylori might alleviate colic or if prevention might work to stop it from developing at all (Steven, 2012).

The aim of this work was to assess the prevalence of H. pylori in Egyptian infants with infantile colic and to determine if $H$. pylori have a causative role in infantile colic.

\section{Patients, Materials and Methods}

The present study is a case-control study including a 100 full term infants, aged between 2 weeks to 4 months. This study was conducted in a primary health care office in Sharkia Governorate. Permission was taken from the local authority and from parents before beginning of this study.

Fifty Infants with infantile colic according to Wessel's Criteria were included in the study. Fifty healthy, age and sex matched, infants without excessive crying, were included as a control group.

Before including the infant full history taking and thorough medical examination to find any apparent cause for this excessive crying. Any infant with apparent cause for this colic was excluded. All the 50 infant cases included were apparently free from any gastrointestinal parasite leading to this excessive colic. Stool examination using hematoxylin and Eosin and Ziehl-Neelsen and modified Trichrome stains (El Naggar et al, 2006) showed no protozoan parasites. Fifty infants without apparent cause for their colic's and the 50 
controls were investigated for $H$. pylori by stool specific antigen (Immunocard Cer Test, BIOTEC, Spain).

Statistical analysis was done using SPSS version 15 software. Data were expressed as mean \pm standard deviation or median (range) for quantitative data, and number and percent for qualitative data. Analysis of quantitative data for significant differences was determined by comparing means using student's test and analysis of qualitative data was compared using chi-square test. A p value of less than 0.05 was considered significant.

\section{Results}

The mean \pm SD of patient and control ages were $8.5 \pm 2.3 \& 7.8 \pm 2.4$ weeks respectively, ranged from 3-16 weeks in cases group and 4- 16 weeks in the control group. Male to female ratio in the cases group 1.4:1 and1.5:1 in controls. H. pylori antigen in stool was detected in 31 cases $(62 \%)$ in contrast to 10 controls $(20 \%)$, which was statistically significant $(\mathrm{p}<0.05)$. Although, there was an increased in incidence of H. pylori stool antigen positives in infant cases born by normal vaginal delivery (NVD) than those born by caesarian section (C.S), but this difference was statistically insignificant ( $p>0.05$ ).

There was an increased incidence of H. pylori antigen positivity in stools of males than females but without significance. No significant association was found between vomiting and antigen positivity, although positive antigen was detected in $69.2 \%$ with vomiting compared to $36.4 \%$ without, but with statistical insignificance $(\mathrm{p}>0.05)$ A total of 45 infants $(90 \%)$ were breast feed and only $5(10 \%)$ had artificial feeding. All 31 infants with positive stool antigen were breast feed (68.9\%). All artificial feeding babies were negative with statistical difference $(\mathrm{p}<0.05)$. The details are given in tables $(1,2,3$, $4,5 \& 6)$.

Table1: Demographic data of groups

\begin{tabular}{|l|c|c|c|c|}
\hline Items & Cases $(\mathrm{n}=50)$ & Control $(\mathrm{n}=50)$ & $\mathrm{T}$ & $\mathrm{P}$ \\
\hline Age $($ Weeks $)$ & & & & \\
Range & $3-16$ & $4-16$ & -1.489 & 0.139 \\
Mean \pm SD & $8.5 \pm 2.3$ & $7.8 \pm 2.4$ & & (NS) \\
\hline Males & $29(58 \%)$ & $30(60 \%)$ & & 1.000 \\
Females & $21(42 \%)$ & $20(40 \%)$ & & (NS) \\
\hline
\end{tabular}

Table 2: H. pylori Antigen in stools of cases and controls

\begin{tabular}{|l|c|c|c|c|c|c|}
\hline H. pylori Antigen & \multicolumn{2}{|c|}{ Cases (50) } & \multicolumn{2}{c|}{ Controls (50) } & & \\
in stool & No & $\%$ & No & $\%$ & $\mathrm{X}^{2}$ & P \\
\hline Positive & 31 & 62 & 10 & 20 & & $<0.0001$ \\
Negative & 19 & 38 & 40 & 80 & 16.536 & (S) \\
\hline
\end{tabular}

Table 3: H. pylori antigen in stool and methods of delivery in cases

\begin{tabular}{|c|c|c|c|c|c|c|}
\hline \multirow{2}{*}{$\begin{array}{l}\text { Antigen } \\
\text { in stool }\end{array}$} & \multicolumn{2}{|c|}{ NVD (15) } & \multicolumn{2}{|c|}{ C.S (35) } & \multirow[b]{2}{*}{$X^{2}$} & \multirow[b]{2}{*}{$\mathrm{P}$} \\
\hline & No & $\%$ & No & $\%$ & & \\
\hline Positive & 10 & 66.6 & 21 & 60 & & 0.902 \\
\hline Negative & 5 & 43.4 & 14 & 40 & 0.015 & (NS) \\
\hline
\end{tabular}


Table 4: H. pylori antigen in stool and sex in cases group

\begin{tabular}{|c|c|c|c|c|c|c|}
\hline \multirow{2}{*}{$\begin{array}{l}\text { Antigen } \\
\text { in stool }\end{array}$} & \multicolumn{2}{|c|}{ Males (22) } & \multicolumn{2}{|c|}{ Females(28) } & \multirow[b]{2}{*}{$\mathrm{X}^{2}$} & \multirow[b]{2}{*}{$P$} \\
\hline & No & $\%$ & No & $\%$ & & \\
\hline Positive & 16 & 72.8 & 15 & 53.5 & & 0.270 \\
\hline Negative & 6 & 27.2 & 13 & 46.5 & 1.215 & (NS) \\
\hline
\end{tabular}

Table 5: Association of vomiting to infantile colic and $H$. pylori antigen in stools

\begin{tabular}{|c|c|c|c|c|c|c|}
\hline \multirow{2}{*}{$\begin{array}{l}\text { Antigen } \\
\text { in stool }\end{array}$} & \multicolumn{2}{|c|}{ Vomiting (39) } & \multicolumn{2}{|c|}{ No Vomiting (11) } & \multirow[b]{2}{*}{$\mathrm{X}^{2}$} & \multirow[b]{2}{*}{$P$} \\
\hline & No & $\%$ & No & $\%$ & & \\
\hline Positive & 27 & 69.2 & 4 & 36.4 & & 0.103 \\
\hline Negative & 12 & 30.8 & 7 & 63.6 & 2.649 & (NS) \\
\hline
\end{tabular}

Table 6: H. pylori antigen in stool and breast feeding

\begin{tabular}{|l|c|c|c|c|c|c|}
\hline $\begin{array}{l}\text { Antigen } \\
\text { in stool }\end{array}$ & \multicolumn{2}{|c|}{ Breast Feeding (45) } & \multicolumn{2}{|c|}{ Artificial feeding (5) } & & \\
\hline No & $\%$ & No & $\%$ & $\mathrm{X}^{2}$ & $\mathrm{P}$ \\
\hline Positive & 31 & 68.9 & 0 & 0 & & 0.0115 \\
\hline
\end{tabular}

\section{Discussion}

Infantile colic is one of the most common problems within the first 3 months of life, affecting as many as 3\% to $28 \%$ of infants. It consists of a behavioral syndrome characterized by paroxysmal, excessive, inconsolable crying without an identifiable cause(s) (Woodgate et al, 2005). Since the discovery of Helicobacter pylori (Marshall and Warren, 1983), a new era of discovery and understanding of gastroduodenal pathology started . H.pylori infection is the most prevalent gastric microbial pathogen in humans. The outcome of chronic infection varied from asymptomatic gastritis to peptic ulcerations to gastric malignancies (Chelimsky et al, 2005). Homan et al. (2012) stated that the antigen stool test is becoming the "gold standard" in prevalence studies, and according to last epidemiologic studies, the prevalence of $H$. pylori infection in childhood is not decreasing any more in the developed world. Siavoshi et al. (2013) stated that vaginal yeast is an important reservoir of $H$. pylori and vaginal yeast is proposed as primary reservoir of $H$. pylori which facilitates $H$. pylori transmission to neonates.

Hassanein et al. (2012) stated that the Cryptosporidium parvum, Giardia lamblia, Entamoeba histolytica and pathogenic Gram-negative organisms were identified in the stool samples with prolonged or severe watery diarrhea in Egyptian infants and children. However, in the present study, the stool examination showed non parasites causing colic or gastrointestinal disturbance. Ankarklev et al. (2012) reported that non-symptomatic Ugandan children suffering from $H$. pylori have associated increased risk factor for other gastrointestinal infections.

Abdelrazak (2012) found significant association between $H$. pylori antigen positivity and infantile colic. This agreed with the present data. In their study to investigate the prevalence of H.pylori antigen in the stools of Norwegian neonates and small children, Arne et al, (2007) found $H$. pylori antigen in stools of $52 \%(36 / 69)$ of the ne- 
onates, in 15\% (7/46) of infants aged 7 days-1 month, and in 5\% (7/134) of children aged 1 month -3 years. They believed that high $H$. pylori antigen detection rate in neonates suggested that transient colonization may occur in the neonatal period. This may explain why infantile colic ended mostly at 4 months.

In this study, there was statistically insignificant increased incidence of $H$. pylori antigen positivity in infants born by NVD than those born by C.S $(\mathrm{P}=0.902)$. Arne et al (2007) in contrast founded that $H$. pylori antigen detection was significantly associated with mode of delivery: 59\% (30/51) with uncomplicated vaginal births were positive compared to only $10 \%(1 / 10)$ of infants delivered by cesarean section ( $\mathrm{P}=0.02)$. Relation between $H$. pylori stool antigen and patients' sex was increased in males $(72.8 \%)$ than females (53.5\%), without significance $(\mathrm{P}=0.27)$. Maria et al. (2005) and Sarah et al. (2007) found no significant sex difference regarding infection. Hestivik et al (2010) found significant difference in male $(49.8 \%)$ versus females $(38.5 \%)$.

In the present study, insignificant increase in vomiting was in association between infantile colic and stool antigen positive cases. This may add a more selection criteria in deciding which baby suffered colic due to $H$. pylori. The present most strange and unexpected result was the absence of positive stool antigen in artificial feeder's babies in contrast to breast feeder ones, which might be due to the presence of probiotics in the artificial milk. This went with Weizman et al. (2005).

\section{Conclusions}

This study is in support of the new theory for the role of $H$. pyloi in the pathogenesis of infantile colic. Vomiting, breast feeding and male gender may increase the stress on the pediatrician to investigate for $H$. pylori infection in infants with infantile colic.

\section{Recommendations}

A longer and wider study is needed to identify the mode of transmission of H. pylori to neonates, prevalence of $H$. pylori in mothers of affected infants and the effect of treatment of $H$. pylori on babies with infantile colic. Advice is to investigate $H$. pylori in infants with infantile colic as well as mothers if indicated and treated her also as she may be a source for her infant infection

\section{References}

Abdelrazak, MA, 2012: Arch Pediatr Adolesc Med.166. 7:648-50.

Algood. HM, Cover, TL, 2006: Helicobacter pylori persistence: An overview of interactions between $H$. pylori and host immune defenses. Clin. Microbiol. Rev.19:597-613.

Ankarklev, J, Hestvik, E, Lebbad, M, Lindh, J, Kaddu, DH, et al, 2012: Common co-infections of Giardia intestinalis and Helicobacter pylori in non-symptomatic Ugandan children. PLoS. Negl. Trop Dis. 6, 8: e1780.

Arne, S, Gaustad, P, Stray-Pedersen, B, 2007: Detection rate of $H$. pylori stool antigen in newborn infants and children. J. Perinat. Med. 35, 2: 155-8.

Chelimsky, G, Czinn, SJ, 2006: Helicobacter pylori infection in children: update. Curr. Opin. Pediatr. 12, 5:4602. 
El-Naggar, SM, el-Bahy, MM, Abd Elaziz, J, el-Dardiry, MA, 2006: Detection of protozoa parasites in stools of diarrheic patients using different techniques. J. Egypt. Soc. Parasitol. 36, 2:487-516.

Ghosh, S, Barr, RG, 2004: Colic and gas. In: Pediatric Gastrointestinal Disease. $4^{\text {th }}$ ed. Hamilton, Ontario: BC Decker Inc.

Gijsbers, CFM, Kneepkens, CMF, Büller, HA, 2006: The role of Helicobacter pylori in recurrent abdominal pain. J. Pediatr. Gastroenterol. Nutri. 42, 5: E34.

Hassanein, S, Abd-El-Latif, M, Hassanin, O, Abd-El-Latif, LM, Ramadan, NI, 2012: Cryptosporidium gastroenteritis in Egyptian children with acute lymphoblastic leukemia: magnitude of problem. Infection 40, 3:279-84.

Herman, M, Le A, 2007: The crying infant. Emerg. Med. Clin. North Am. 25, 4:1137-59.

Hestivik, E, Kaddu-Mullindwa, DH, 2010: Helicobacter pylori in apparently healthy children in urban Kampala, Ughanda. BMC Gastroentro. 16, 10:62.

Homan, M, Hojsak, I, Kolaček, S, 2012: Helicobacter pylori in pediatrics. Helicobacter 17, 1:S43-8.

Kato, S, Sherman, PM, 2005: What is new related to Helicobacter pylori infection in children and teenagers? Arch. Pediatr. Adol. Med. 159:415-21.

Maria, T, Meta, C, et al, 2006: $H$. pylori infection, follow up. www. Emedicine. medscape.

Özen, A, Ertem, D, Pehlivanoglu, E, 2006: Natural history and symptomatology of $H$. pylori in childhood and factors determining the epidemiology of infection. J. Pediatr. Gastroenterol. Nutri. 42, 4:398-404.

Reijneveld, SA, Brugman, E, Hirasing, R, 2001: Excessive infant crying: Impact of varying definitions. Pediatr. 108:893-7.

Roberts, DM, Ostapchuk, M, O' Brien, J, 2004: University of Louisville School of Medicine, Louisville, Kentucky Am. Fam. Physician 70, 4:735-40.

Sarah, C, et al, 2008: The epidemiology of $H$. pylori infection in African refugee children resettled in Australia. MJA 189, 8:438-41.

Siavoshi, F, Taghikhani, A, Malekzadeh, R, Sarrafnejad, A, Kashanian, et al, 2013: The role of mother's oral and vaginal yeasts in transmission of Helicobacter pylori to neonates. Arch. Iran Med. 16, 5:288-94.

Steven, F, 2012: $H$. pylori linked to infantile colic. Medscape.

Talachian, E, Bidari, A, Rezaie, MH, 2008: Incidence and risk factors for infantile colic in Iranian infants. Wld. J. Gastroenterol. 14, 29:4662-6.

Talley, NJ, Richter, J, 2006: Nobel prize in medicine awarded to a gastroenterologist in 2005. Am. J. Gastroenterol. 101:21

Weizman, Z, Asli, G, Alsheikh, A, 2005: Effect of a probiotic infant formula on infections in child care centers: Comparison of two probiotic agents. Pediatr. 115:5-9.

Woodgate, P, Cooke, L, Webster, H, 2005: Medical therapy for infantile colic. Cochrane Database Syst. Rev. 4:CD004382. 